\title{
The effects of burning and grazing on soil carbon dynamics in managed Peruvian tropical montane grasslands
}

\author{
Viktoria Oliver $^{1, \mathrm{a}}$, Imma Oliveras ${ }^{2}$, Jose Kala ${ }^{3}$, Rebecca Lever ${ }^{4, \mathrm{a}}$, and Yit Arn Teh ${ }^{1, \mathrm{a}}$ \\ ${ }^{1}$ School of Biological Sciences, University of Aberdeen, Cruickshank Building, \\ St. Machar Drive, AB24 3UU Aberdeen, UK \\ ${ }^{2}$ Environmental Change Institute, School of Geography and the Environment, University of Oxford, \\ South Parks Road, OX13QY Oxford, UK \\ ${ }^{3}$ Faculty of Science, Department of Biology, Universidad Nacional de San Antonio Abad del Cusco, Cusco, Peru \\ ${ }^{4}$ Department of Life and Environmental Sciences, University of California, Merced 5200 North Lake \\ Rd. Merced, CA 95343, USA \\ a formerly at: the School of Geography and Geosciences, University of St Andrews, St Andrews, UK
}

Correspondence: Viktoria Oliver (v.oliver@abdn.ac.uk)

Received: 29 March 2017 - Discussion started: 6 April 2017

Revised: 25 September 2017 - Accepted: 28 September 2017 - Published: 14 December 2017

\begin{abstract}
Montane tropical soils are a large carbon $(\mathrm{C})$ reservoir, acting as both a source and a sink of $\mathrm{CO}_{2}$. Enhanced $\mathrm{CO}_{2}$ emissions originate, in large part, from the decomposition and losses of soil organic matter (SOM) following anthropogenic disturbances. Therefore, quantitative knowledge of the stabilization and decomposition of SOM is necessary in order to understand, assess and predict the impact of land management in the tropics. In particular, labile SOM is an early and sensitive indicator of how SOM responds to changes in land use and management practices, which could have major implications for long-term carbon storage and rising atmospheric $\mathrm{CO}_{2}$ concentrations. The aim of this study was to investigate the impacts of grazing and fire history on soil $\mathrm{C}$ dynamics in the Peruvian montane grasslands, an understudied ecosystem, which covers approximately a quarter of the land area in Peru. A density fractionation method was used to quantify the labile and stable organic matter pools, along with soil $\mathrm{CO}_{2}$ flux and decomposition measurements. Grazing and burning together significantly increased soil $\mathrm{CO}_{2}$ fluxes and decomposition rates and reduced temperature as a driver. Although there was no significant effect of land use on total soil C stocks, the combination of burning and grazing decreased the proportion of $\mathrm{C}$ in the free light fraction (LF), especially at the lower depths (10-20 and 20$30 \mathrm{~cm}$ ). In the control soils, $20 \%$ of the material recovered was in the free LF, which contained $30 \%$ of the soil C con-
\end{abstract}

tent. In comparison, the burnt-grazed soil had the smallest recovery of the free LF $(10 \%)$ and a significantly lower C content $(14 \%)$. The burnt soils had a much higher proportion of $\mathrm{C}$ in the occluded LF (12\%) compared to the not-burnt soils $(7 \%)$ and there was no significant difference among the treatments in the heavy fraction $(\mathrm{F})(\sim 70 \%)$. The synergistic effect of burning and grazing caused changes to the soil $\mathrm{C}$ dynamics. $\mathrm{CO}_{2}$ fluxes were increased and the dominant temperature driver was obscured by some other process, such as changes in plant $\mathrm{C}$ and $\mathrm{N}$ allocation. In addition, the free LF was reduced when these two anthropogenic activities took place on the same site - most likely a result of reduced detritus being incorporated into the soil. A positive finding from this study is that the total soil C stocks were not significantly affected and the long-term $(+10$ years) $\mathrm{C}$ storage in the occluded LF and heavy F were not negatively impacted. Possibly this is because of low-intensity fire, fire-resilient grasses and because the grazing pressure is below the threshold necessary to cause severe degradation.

\section{Introduction}

High-altitude montane grasslands (3200-4500 ma.s.1.) account for a major proportion of land cover in the Andes, particularly in Peru, where they make up approximately $25 \%$ of 
land cover (Feeley and Silman, 2010). Every year, especially in the dry season, large areas of these grasslands are burned to support traditional cattle grazing, which has been apparent since the early 1500s (Luteyn, 1992). Fires for agricultural clearing and maintenance of these highly productive forage grasses are of considerable importance in these ecosystems and for the livelihood of the local people (Sarmiento and Frolich, 2002). To some extent, this natural system is tolerant of these management practices (Ramsay, 1992). However, in recent years, it has become apparent that the combination of global warming and the considerable pressure from agricultural expansion have resulted in increased fire occurrence and the subsequent destruction of tropical montane cloud forest (Cochrane and Ryan, 2009). Evidence of fire scars and charcoal deposits along the forest-puna tree line demonstrate a gradual encroachment into the adjacent tropical montane cloud forest (Di Pasquale et al., 2008).

Previous research in these Andean montane grasslands have measured large soil C stores (Gibbon et al., 2010; Oliveras et al., 2014b). However, despite the concern for the effects of land management practices, there are very few studies on soil $\mathrm{C}$ dynamics in this tropical region of the $\mathrm{Pe}$ ruvian Andes. It is particularly unclear how land management affects the soil $\mathrm{C}$ dynamics and sequestration potential under the influence of grazing and burning. For example, Oliveras et al. (2014b) found that grazing and fire in montane grasslands resulted in decreased net primary productivity (NPP), but there were no differences between these two disturbances. Studies in other montane grasslands have found that an increase in the frequency of fire events can reduce the amount of soil organic matter (SOM) in the top soil (Knicker, 2007), or it may increase the biomass growth period afterwards, causing more detritus to accumulate in the upper soil layers (Ojima et al., 1994).

SOM influences many soil functions and occupies a key position in the global C cycle (Lal, 2004). It is a highly heterogeneous and dynamic composite of organic molecules (such as polysaccharides, lignin, aliphatic biopolymers, tannins, lipids, proteins and amino sugars) derived from progressively decomposed plant, animal and microbial material (Zimmermann et al., 2007; Totsche et al., 2010).

The turnover of SOM is a balance between the inputs of material into the soil (e.g. above- and belowground litter, dissolved organic C) and the rate of SOM decomposition. The rate of decomposition is a consequence of complex interactions and interdependence between the organic matter and its environment. These include biochemical recalcitrance (compound chemistry), physical protection (adsorption of SOM to reactive surfaces of mineral particles and the physical protection within aggregates) (Six and Jastrow, 2002), climate (temperature, water availability), soil acidity, soil redox state (Raich and Schlesinger, 1992; Kirschbaum, 1995; Stockmann et al., 2013) and functional composition of the soil microbial community (Allison, 2012). More recently, it has been considered that $\mathrm{C}$ stability is mainly dependent on its biotic and abiotic environment, rather than on the molecular structures of C inputs (Schmidt et al., 2011).

In order to understand soil $\mathrm{C}$ dynamics, a variety of measurable $\mathrm{C}$ pools have been identified within SOM according to biological stability, decomposition rate and turnover time (Krullet al., 2003; Trumbore, 2009; Stockmann et al., 2013). Specifically, SOM can be classified into three significant pools: active, resistant and inert (Trumbore, 1993; Bol et al., 2009). The active (also termed the labile) pool contains a high $\mathrm{C}$ concentration and is composed of physically available and chemically mineralizable plant material (sugars and amino acids) (Zou et al., 2005; Petrokofsky et al., 2012). Consequently, it is less stable and plays an essential role in the short-term nutrient cycles, with a turnover ranging from days to a few years (Wander, 2004).

The resistant pools (also known as intermediate, slow, recalcitrant or refractory) (Krull et al., 2003) contain physically and chemically transformed material residing on and within the surface of clay and silt minerals. The combination of physically protected and biochemically recalcitrant SOM (alkyl and lignin-derived aromatic C) (Coleman and Jenkinson, 1996; Petrokofsky et al., 2012) causes this C pool to have a turnover on decadal timescales (Six et al., 2002). This pool is important for long-term $\mathrm{C}$ sequestration, sorption, cation exchange capacity and soil water-holding capacity (Wander, 2004).

The inert (or passive) pool has a turnover time of decades to millennia and is central to the stabilization of humus and soil aggregation. This pool contains highly carbonized organic material that is resistant to microbial mineralization (Brodowski et al., 2006), as well as charcoal (i.e. black C), and is considered to have a recalcitrant structure due to its high degree of aromaticity (Derenne and Largeau, 2001). Although this pool has a low $\mathrm{C}$ concentration, it can form the largest soil $\mathrm{C}$ fraction, especially in fine-textured tropical soils (Marin-Spiotta et al., 2009), and can be unaffected by land management or climate, making it the most stable and relevant for long-term C storage (Falloon and Smith, 2000).

Land use change and land management studies have found that, even when the bulk soil $\mathrm{C}$ does not appear to be affected, the distribution of SOM pools may change due to their differing sensitivities to environmental forcing or external perturbation (Zimmermann et al., 2007; Marin-Spiotta et al., 2009). It is commonly accepted that the labile pools are the most sensitive to changes in vegetation management and are identified as an indicator of soil quality changes in the short term (Kennedy and Papendick, 1995; Islam and Weil, 2000). However, while several studies have found the labile pool to be more sensitive to land management (Conant et al., 2011; Wang and Wang, 2011), others have found no discernible effect on pool size (Leifeld and Kögel-Knabner, 2005). For instance, labile pools can either increase (Poeplau and Don, 2013) or decrease, depending on the magnitude of C inputs (e.g. roots, litter fall) or the level of grazing intensity (Figueiredo et al., 2010) 


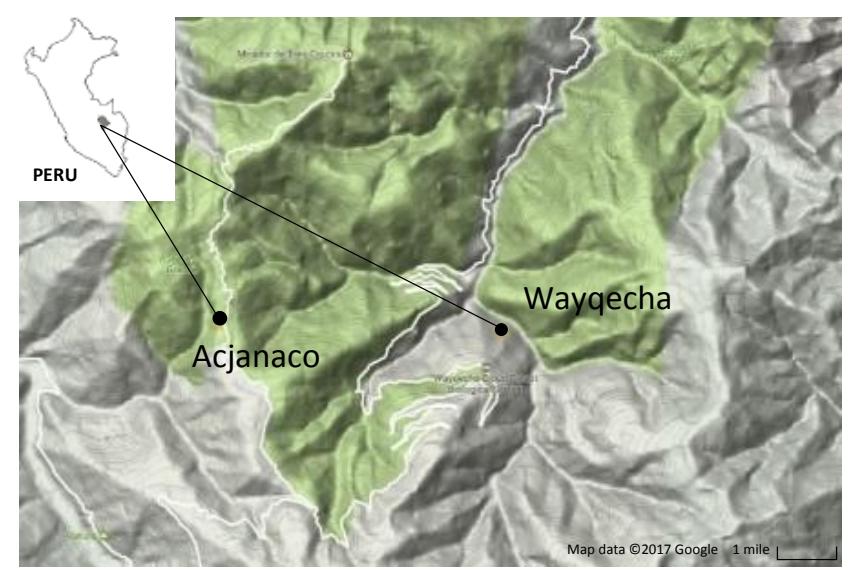

Figure 1. Map illustrating the two sites in the high-elevation montane grassland (circles). The green area represents the Manu National Park.

Quantification of different SOM pools and how they respond to land management is important for understanding $\mathrm{C}$ dynamics and their relative role in the global $\mathrm{C}$ cycle (Trumbore, 1997; Bayer et al., 2001). SOM turnover models use conceptual SOM pools, but now it is possible to substitute these pools with measurable fractions of SOC (soil organic carbon) (Skjemstad et al., 2004; Zimmermann et al., 2007). Identification and separation of these SOC pools has led to many methods of soil fractionation, including physical (size, density, aggregation) and chemical (solubility, mineralogy). Density fractionation has been very successful at assessing the short and long-term dynamics of soil C storage (Christensen, 2001; Marín-Spiotta et al., 2008; Marin-Spiotta et al., 2009; Mueller and Koegel-Knabner, 2009). This procedure is based on the application of several disaggregating treatments and dispersion, followed by density separations using organic solutions or inorganic salts (von Lützow et al., 2007), and represents a variety of pools that are related to microbial function based on the location within the soil matrix and degree of association with minerals (Krull et al., 2003; Trumbore, 2009). Six et al. (2002) used sodium polytungstate (SPT) to isolate light and heavy fractions (F) of SOM because of its high viscosity at high concentrations. This method was later adapted by Marin-Spiotta et al. (2009) and Mueller and Koegel-Knabner (2009) to separate SOM pools into three distinct fractions: the free light fraction (LF) (active pool), occluded light fraction (resistant pool) and heavy fraction (inert pool).

The aim of this study is to gain further mechanistic insights into the impact of land use management on soil $\mathrm{C}$ losses and different SOM fractions in Peruvian montane grasslands. In order to investigate the effects of burning and grazing on soil $\mathrm{C}$ stocks, we took advantage of an ongoing burning-grazing study that was established in July-August 2010 (Oliveras et al., 2014b) The specific objectives of this study were to a. quantify and compare the effect of fire history and grazing on total SOC stocks and the three main SOM pools (free light fraction, occluded light fraction and heavy fraction) at different soil depths down to $30 \mathrm{~cm}$,

b. quantify differences in soil respiration and decomposition rates on historically burnt and grazed sites, and

c. evaluate the role of soil temperature and soil moisture in regulating soil respiration.

\section{Material and methods}

\subsection{Site descriptions}

The undulating terrain in the Peruvian montane grassland is commonly used by the local communities for extensive cattle grazing and, although the study area is in the Manu National Park, burning and grazing still occasionally takes place. This study included two sites that were identified as being burnt in 2003 (Wayqecha) and 2005 (Acjanaco) (Fig. 1). The site at Wayqecha is located at approximately $3085 \mathrm{~m}$ a.s.l. in the Wayqecha Biological Station $\left(13^{\circ} 18^{\prime} \mathrm{S}\right.$, $71^{\circ} 58^{\prime} \mathrm{W}$ ), where the mean annual precipitation is $1560 \mathrm{~mm}$ and mean annual air temperature is $11.8^{\circ} \mathrm{C}$. The site at Acjanaco $\left(13^{\circ} 17^{\prime} \mathrm{S}, 71^{\circ} 63^{\prime} \mathrm{W}\right)$ is located on the Manu National Park border at $3400 \mathrm{~m}$ a.s.l. and has a mean annual precipitation of $760 \mathrm{~mm}$ and mean annual air temperature of $6.8^{\circ} \mathrm{C}$ (Girardin et al., 2010) (Table 2). The wet season runs from October to March and there are more noticeable variations in diurnal temperatures than seasonal differences (Zimmermann et al., 2009). Grass species composition are similar on both sites (Calamagrostis longearistata, Scirpus rigidus and Festuca dolichophylla) (Oliveras et al., 2014a). The soils are classified as Umbrisols and are typically only $30 \mathrm{~cm}$ deep with a thick acidic organic rich A layer overlying a thin, stony $\mathrm{B}$ and $\mathrm{C}$ horizons and no $\mathrm{O}$ horizon (Gibbon et al., 2010) (soil characteristics shown in Table 1). The sites are predominantly on Palaeozoic ( $\sim 450 \mathrm{Ma})$ meta-sedimentary mudstones $(\sim 80 \%)$ (Carlotto et al., 1996).

\subsection{Experimental design}

The sites were set up in a factorial design in JulyAugust 2010 to investigate the effects of fire (burnt, not burnt) and grazing (grazed, not grazed) on soil C stocks, soil $\mathrm{C}$ fractions and soil respiration. The two sites (Acjanaco and Wayqecha) were selected to include a burnt and unburnt area no more than $200 \mathrm{~m}$ apart, which were then split into two subplots $(2 \times 2 \mathrm{~m})$ - one with fencing, constructed 2 years prior to sampling, to stop cattle grazing and one left unfenced. Each site contained a factorial combination of the two treatments, i.e. burnt-not grazed, burnt-grazed, not burnt-grazed and not burnt-not grazed (Fig. 2). The fire at Acjanaco occurred in 2005 and, before that, this area had 


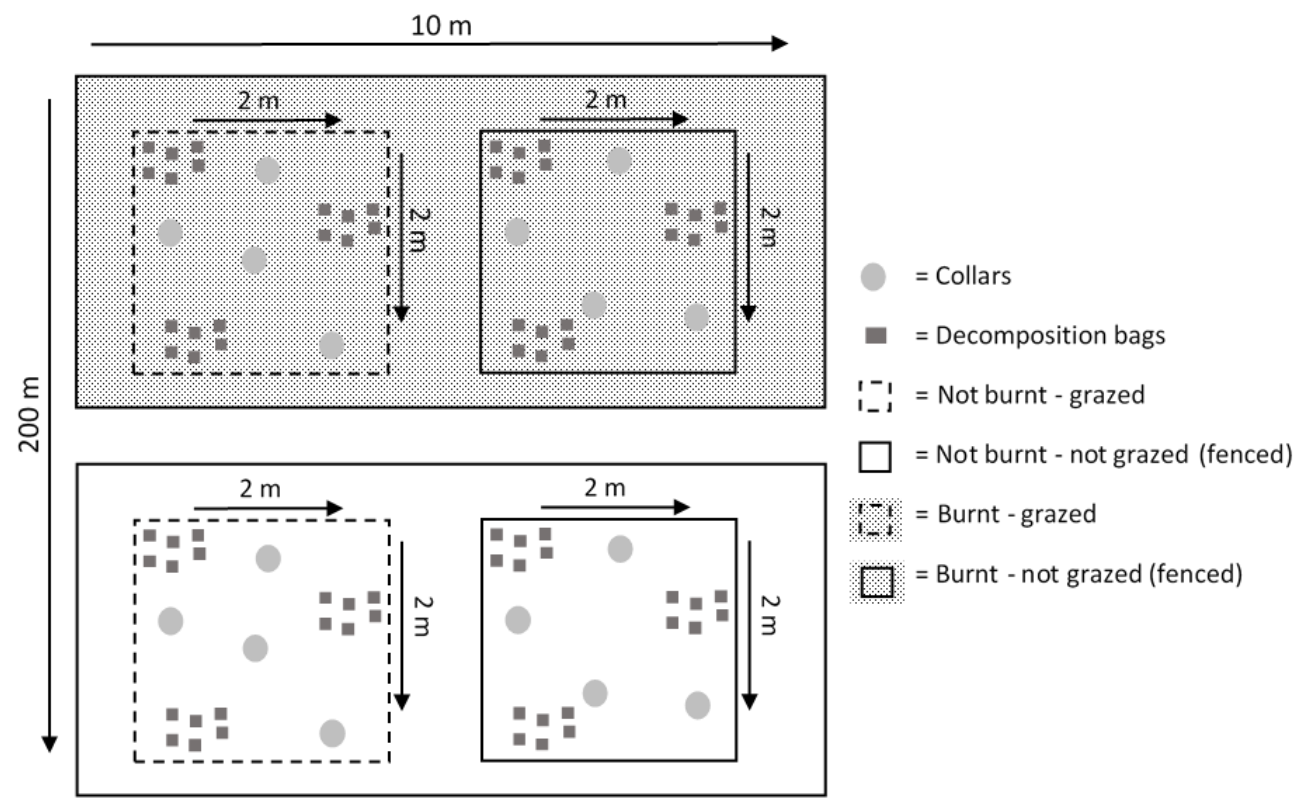

Figure 2. Schematic diagram illustrating the set-up of the plots. This experimental design was established at both Acjanaco and Wayqecha. Soils from three pits in each plot were collected for analysis.

Table 1. Soil description for each land management at Wayqecha and Acjanaco (mineral soil particle size taken from Diem et al., 2017).

\begin{tabular}{|c|c|c|c|c|c|c|c|}
\hline \multirow[t]{3}{*}{ Site } & \multirow[t]{3}{*}{ Land use } & \multirow{2}{*}{\multicolumn{2}{|c|}{$\begin{array}{l}\text { Bulk density } \\
\qquad\left(\mathrm{g} \mathrm{cm}^{-3}\right)\end{array}$}} & \multirow[t]{2}{*}{$\mathrm{pH}$} & \multicolumn{3}{|c|}{ Mineral soil particle size } \\
\hline & & & & & Sand & Silt & Clay \\
\hline & & $0-10 \mathrm{~cm}$ & $10-20 \mathrm{~cm}$ & $0-10 \mathrm{~cm}$ & & $0-10 \mathrm{~cm}$ & \\
\hline \multirow{4}{*}{ Wayqecha (2003) } & Grazed-burnt & $0.45 \pm 0.03$ & $0.37 \pm 0.05$ & $4.3 \pm 0.2$ & & & \\
\hline & Not grazed-burnt & $0.25 \pm 0.13$ & $0.47 \pm 0.03$ & $4.1 \pm 0.1$ & & & \\
\hline & Grazed-not burnt & $0.43 \pm 0.01$ & $0.61 \pm 0.10$ & $4.3 \pm 0.1$ & & & \\
\hline & Not grazed-not burnt & $0.30 \pm 0.07$ & $0.46 \pm 0.05$ & $4.5 \pm 0.2$ & $43.0 \pm 3.2$ & $54.4 \pm 3.0$ & $2.6 \pm 0.2$ \\
\hline \multirow[t]{4}{*}{ Acjanaco (2005) } & Grazed-burnt & $0.41 \pm 0.03$ & $0.47 \pm 0.05$ & $4.8 \pm 0.2$ & & & \\
\hline & Not grazed-burnt & $0.40 \pm 0.02$ & $0.45 \pm 0.06$ & $4.4 \pm 0.2$ & & & \\
\hline & Grazed-not burnt & $0.34 \pm 0.03$ & $0.35 \pm 0.03$ & $4.1 \pm 0.1$ & & & \\
\hline & Not grazed-not burnt & $0.36 \pm 0.06$ & $0.48 \pm 0.13$ & $5.0 \pm 0.3$ & & & \\
\hline
\end{tabular}

not been burnt since the mid-1970s. The more recent fire occurred in Wayqecha in 2003, and there is no information about the disturbance history before 2003 .

\subsection{Soil respiration and environmental measurements}

On each plot, four permanent PVC (polyvinyl chloride) chamber bases (diameter $20 \mathrm{~cm}$, height $10 \mathrm{~cm}$ ) were deployed randomly for the measurement of soil surface $\mathrm{CO}_{2}$ fluxes, which took place at an interval once every two months from July 2011 to July 2012. Soil respiration measurements were quantified using a static flux chamber technique with a Vaisala CARBOCAP ${ }^{\circledR}$ carbon dioxide probe and temperature sensor fitted inside a PVC cylindrical chamber (diameter $20 \mathrm{~cm}$, height $20 \mathrm{~cm}$ ) covered with a gas-tight lid. The rate of $\mathrm{CO}_{2}$ accumulation was measured every $30 \mathrm{~s}$ for $3 \mathrm{~min}$ by placing the chamber on the fixed chamber base with a gas-tight rubber seal. Simultaneously, air temperature and atmospheric pressure were measured, using a type $\mathrm{K}$ thermocouple (Omega Engineering Ltd., UK) and Garmin GPSmap 60CSx (Garmin Ltd., USA).

Flux rates were calculated in R 3.0.2 (R_Core_Team, 2012) using the HMR package (Pedersen et al., 2010) by plotting the headspace concentration (ppm) against time (minutes) for each collar, which gave a linear or non-linear regression, depending on the best fit.

In addition, soil temperature (at 5 and $10 \mathrm{~cm}$ depth) and soil moisture (at $10 \mathrm{~cm}$ depth) were simultaneously measured in three locations adjacent to the collars using an ML2x ThetaProbe equipped with $12 \mathrm{~cm}$ rods (Delta-T Ltd., 
Table 2. Annual and seasonal mean soil temperature, VWC, and $\mathrm{CO}_{2}$ flux for Wayqecha and Acjanaco for each land management system. Different letters down the columns represent significant differences between sites.

\begin{tabular}{lrrr}
\hline Site/land use & $\begin{array}{r}\text { Soil temp. }\left({ }^{\circ} \mathrm{C}\right) \\
\text { at } 5 \mathrm{~cm}\end{array}$ & $\begin{array}{r}\text { VWC }(\%) \\
\text { at } 5 \mathrm{~cm}\end{array}$ & $\begin{array}{r}\mathrm{CO}_{2} \text { flux } \\
\left(\mu \mathrm{mol} \mathrm{m} \mathrm{m}^{-1}\right)\end{array}$ \\
\hline Wayqecha (2003) & $14.7 \pm 0.1$ & $62.3 \pm 0.4$ & $1.30 \pm 0.08$ \\
Grazed-burnt & $15.3 \pm 0.3^{\mathrm{a}}$ & $63.4 \pm 0.3^{\mathrm{ab}}$ & $1.88 \pm 0.23^{\mathrm{a}}$ \\
Grazed-not burnt & $14.5 \pm 0.2^{\mathrm{ab}}$ & $63.8 \pm 0.2^{\mathrm{ab}}$ & $1.07 \pm 0.07^{\mathrm{a}}$ \\
Not grazed-burnt & $14.6 \pm 0.3^{\mathrm{ab}}$ & $60.9 \pm 1.0^{\mathrm{c}}$ & $0.99 \pm 0.08^{\mathrm{bc}}$ \\
Not grazed-not burnt & $14.1 \pm 0.2^{\mathrm{a}}$ & $62.5 \pm 0.8^{\mathrm{bc}}$ & $1.10 \pm 0.07^{\mathrm{ab}}$ \\
Dry season & $14.1 \pm 0.2$ & $61.4 \pm 0.8$ & $1.35 \pm 0.16$ \\
Wet season & $15.1 \pm 0.20$ & $63.8 \pm 0.3$ & $1.31 \pm 0.10$ \\
Minimum & 11.6 & 29.9 & 0.22 \\
Maximum & 18 & 65.8 & 8.33 \\
\hline Acjanaco (2005) & $11.6 \pm 0.1$ & $64.5 \pm 0.1$ & $0.79 \pm 0.03$ \\
Grazed-burnt & $12.0 \pm 0.2^{\mathrm{c}}$ & $64.0 \pm 0.2^{\mathrm{ab}}$ & $0.82 \pm 0.05^{\mathrm{bc}}$ \\
Grazed-not burnt & $11.5 \pm 0.2^{c d}$ & $64.5 \pm 0.2^{\mathrm{ab}}$ & $0.84 \pm 0.07^{\mathrm{bc}}$ \\
Not grazed-burnt & $11.9 \pm 0.1^{c d}$ & $64.2 \pm 0.2^{\mathrm{ab}}$ & $0.77 \pm 0.05^{\mathrm{c}}$ \\
Not grazed-not burnt & $10.8 \pm 0.1^{d}$ & $65.1 \pm 0.2^{\mathrm{a}}$ & $0.72 \pm 0.05^{\mathrm{c}}$ \\
Dry season & $11.6 \pm 0.1$ & $63.8 \pm 0.2$ & $0.81 \pm 0.04$ \\
Wet season & $11.7 \pm 0.1$ & $65.1 \pm 0.1$ & $0.74 \pm 0.03$ \\
Minimum & 9.5 & 57.1 & 0.09 \\
Maximum & 13.7 & 67.7 & 2.69 \\
\hline Grazed-burnt & $13.8 \pm 0.2^{\mathrm{a}}$ & $63.7 \pm 0.2^{\mathrm{a}}$ & $1.35 \pm 0.13^{\mathrm{a}}$ \\
Grazed-not burnt & $13.2 \pm 0.2^{\mathrm{a}}$ & $64.1 \pm 0.1^{\mathrm{a}}$ & $0.95 \pm 0.05^{\mathrm{a}}$ \\
Not grazed-burnt & $13.3 \pm 0.2^{\mathrm{a}}$ & $62.6 \pm 0.5^{\mathrm{a}}$ & $0.88 \pm 0.05^{\mathrm{a}}$ \\
Not grazed-not burnt & $12.6 \pm 0.2^{\mathrm{a}}$ & $63.8 \pm 0.4^{\mathrm{a}}$ & $0.91 \pm 0.05^{\mathrm{a}}$ \\
\hline
\end{tabular}

UK) and type $\mathrm{K}$ thermocouples (Omega Engineering Ltd., Manchester, UK).

\subsection{Soil sampling and analysis}

Soil sampling. A total of $50 \mathrm{~g}$ of soil samples were taken in July 2012 with six replicates at $0-5,5-10,10-20$ and 20 $30 \mathrm{~cm}$ depths at each site. In many instances, the soil depths were shallow before reaching the bedrock, so samples were only taken at $20-30 \mathrm{~cm}$ where possible. Soil samples were air dried and sieved with a $2 \mathrm{~mm}$ mesh sieve before being shipped to the University of St Andrews for all further analysis (Brown and Lugo, 1982).

Bulk density. Soil bulk density was determined by the soil core method (Klute, 1986). Undisturbed soil cores $\left(30 \mathrm{~cm}^{3}\right)$ were taken from three soil pits at $0-10,10-20$ and $20-30 \mathrm{~cm}$. The samples were dried at $105^{\circ} \mathrm{C}$ for $48 \mathrm{~h}$ and bulk density was estimated as the mass of oven-dried soil divided by the core volume.

Soil fractionation. Soils C fractions were separated using a method developed by Marín-Spiotta et al. (2008) and Mueller and Koegel-Knabner (2009). This method is useful for separating SOM based on the location within the soil matrix and the degree of association with minerals. Prior to the experiment, a sub-sample of soil was taken for moisture correction. The air-dried soil material $(15 \mathrm{~g})$ was sieved in a $2 \mathrm{~mm}$ mesh sieve to remove any living roots and larger organic material, then saturated with $60 \mathrm{~mL}$ sodium polytungstate solution (NaPT, $\mathrm{Na}_{6}\left[\mathrm{H}_{2} \mathrm{~W}_{12} \mathrm{O}_{40}\right]$, Sometu, Germany) at a density of $1.85 \mathrm{~g} \mathrm{~mL}^{-1}$, and centrifuged for $45 \mathrm{~min}$ at $3600 \mathrm{rpm}$ and allowed to settle overnight. The floating free light fraction was aspirated via a pump and rinsed with $500 \mathrm{~mL}$ of deionized water through a $0.4 \mu \mathrm{m}$ polycarbonate filter (Whatman Nuclepore Track-Etched Membrane) to remove residual NaPT. The remaining slurry was further saturated with $60 \mathrm{~mL}$ sodium polytungstate solution $\left(1.4 \mathrm{~g} \mathrm{~cm}^{-3}\right)$, mixed using a benchtop mixer (Mixer/Vortexer - BM1000) for $1 \mathrm{~min}$ at $3200 \mathrm{rpm}$ and dispersed ultrasonically (N10318 Sonics VCX500 Vibra-Cell ultrasonic processor) for $3 \mathrm{~min}$ at $70 \%$ pulse for a total input of $200 \mathrm{~J} \mathrm{~mL}^{-1}$. Centrifugation (45 min at $3600 \mathrm{rpm}$ ) was used to separate the occluded light fraction from the mineral residue and allowed to sit overnight to achieve further separation by flotation of organic debris and settling of clay particles in solution. The occluded LF was then aspirated via a pump and rinsed. In order to remove the NaPT from the heavy fraction, deionized water was mixed with the material and centrifuged for $15 \mathrm{~min}$ at $4000 \mathrm{rpm}$ five times. All fractions were oven dried at $100^{\circ} \mathrm{C}$ overnight, weighed, and physically ground to a fine powder before $\mathrm{C}$ analysis and isotope analysis. The recovery of the soil C density fractions was $96 \%$. 
Carbon analysis. Bulk soils were ground and homogenized using a grinding mill (Planetary Mono Mill PULVERISETTE) in preparation for $\mathrm{C}$ analysis at the University of St Andrews laboratories using a Finnigan Delta plus XP gas source mass spectrometer coupled to an elemental analyser (EA-IRMS).

Decomposition estimates. A decomposition experiment was set up as an additional estimate of soil organic matter mineralization, using birch wood sticks as a common substrate. Five sticks were placed in a mesh bag with three $2 \mathrm{~cm}$ holes cut into each bag to allow accessibility for both microfauna and fauna. In July 2011, 18 bags were buried at $10 \mathrm{~cm}$ depth in groups of 6 , in close proximity on each plot (Fig. 2). Three bags, one from each group, were collected every 2 months. The sticks were weighed before the experiment started and again after collection, once they were air dried, to determine mass loss. The rate of decomposition was then calculated from the slope of a linear regression with time against mass loss.

\subsection{Statistical analysis}

Statistical analyses were conducted in $\mathrm{R}$ version 3.0.2 (R_Core_Team, 2012). Outliers were observed by visual inspection of the box plots where points outside of the hinges (third quartile) were removed and the data were checked for normal distributions. The $\mathrm{CO}_{2}$ flux and volumetric water content (VWC) data were not normally distributed and therefore log transformed prior to parametric statistical analysis. Linear mixed effect models were conducted to identify any relationships between the environmental variables and soil characteristics with soil $\mathrm{CO}_{2}$ fluxes for each site individually. In this respect, mixed-model restricted maximum likelihood analyses (REMLs) were computed using the lme4 package (Bates et al., 2014) to include random intercepts for each collar and for the effect of grazing nested within the burnt sites. Analysis of variance (ANOVA) and Tukey's honest significant difference (HSD) post-hoc test were used to examine statistically significant differences between means of the environmental data among the sites. Linear regression analysis was used on the decomposition data and tested to identify any relationships with the soil $\mathrm{CO}_{2}$ fluxes. Differences in soil $\mathrm{C}$ between the areas were analysed using a oneway ANOVA and Tukey's HSD post-hoc test after testing for normality and homogeneity of variances.

\section{Results}

\subsection{Soil respiration and environmental drivers}

The overall annual $\mathrm{CO}_{2}$ mean for the pooled dataset, including all types of land management, was $1.04 \pm 0.04 \mu \mathrm{mol} \mathrm{m}{ }^{-2} \mathrm{~s}^{-1}$. The combination of grazing and burning significantly increased soil $\mathrm{CO}_{2}$ fluxes at Wayqecha (2003) but not at Acjanaco (Fig. 3). Regardless of land use, the plots at Wayqecha (2003) had greater variability and overall higher mean annual soil temperature $\left(15^{\circ} \mathrm{C}\right)$ and $\mathrm{CO}_{2}$ flux $\left(1.30 \pm 0.08 \mu \mathrm{mol} \mathrm{m}{ }^{-2} \mathrm{~s}^{-1}\right)$ compared to the sites in Acjanaco (2005) $\left(12^{\circ} \mathrm{C}\right.$ and $\left.0.79 \pm 0.03 \mu \mathrm{mol} \mathrm{m}^{-2} \mathrm{~s}^{-1}\right)$ (Table 2). The highest measured temperatures and $\mathrm{CO}_{2}$ fluxes at Wayqecha were synchronously recorded during July 2011, November 2012 and March 2012, whereas at Acjanaco the changes in $\mathrm{CO}_{2}$ flux with season and temperature were less pronounced.

Seasons (which run from October to March), soil and air temperature were the main drivers of soil respiration ( $p$ values $=0.031,9.3 \times 10^{-7}$ and 0.0001 , respectively), with higher temperatures having a positive effect on soil $\mathrm{CO}_{2}$ fluxes. However, when analysing the grazed-burnt plots at both Wayqecha and Acjanaco, there was no relationship between $\mathrm{CO}_{2}$ fluxes and temperature or any of the other environmental variables measured.

\subsection{Decomposition rates}

The decomposition of the birch wood sticks was slow, with an overall average weight loss of $\sim 20 \%$ in 1 year. Grazing alone appeared to slightly increase the rate of decomposition when all the data were pooled together (grazed: $y=104.53-4.23 \times, R^{2}=0.98$; not grazed: $\left.y=103.63-3.11, \quad R^{2}=0.94\right)$, but burning alone did not affect decomposition rate (burnt: $y=103.34-3.57$, $R^{2}=0.96 ;$ not burnt: $\left.y=104.82-3.76 \times, \quad R^{2}=0.97\right)$ (Fig. 4). Site-specific differences were observed for decomposition rates; for example, decomposition was generally faster at Wayqecha compared to Acjanaco. In particular, the grazed-not-burnt plot at Wayqecha showed the fastest overall rate of decomposition $\left(y=101.98-0.19 \times, R^{2}=0.77\right)$ and the not-grazed-not-burnt plots (controls) had the slowest decomposition rates (Fig. 4) on both sites.

Decomposition was not a strong overall predictor for $\mathrm{CO}_{2}$ fluxes for the pooled dataset, although there were some strong correlations between these two variables at specific study sites. For example, there was a strong relationship between decomposition and soil $\mathrm{CO}_{2}$ fluxes at Acjanaco $\left(y=0.38-0.18 \times, R^{2}=0.99\right)$ (i.e. faster mass loss higher soil respiration), whereas at Wayqecha this relationship was weak $\left(y=1.56-0.06 \times, R^{2}=0.07\right)$. Land use did not appear to influence the decomposition-rate-soil- $\mathrm{CO}_{2}$-flux relationship.

\subsection{Soil C stocks}

Grazing, burning and the combination of burning and grazing did not significantly alter total soil $\mathrm{C}$ at any depth down to $30 \mathrm{~cm}$ on either of the sites (Table 3). The overall sum of all the measured depths showed signs of a decrease in $\mathrm{C}$ stocks on the grazed soils, from $189 \pm 32 \mathrm{Mg} \mathrm{Cha}^{-1}$ on the undisturbed sites to $130 \pm 20 \mathrm{Mg} \mathrm{Cha}^{-1}$ on the grazedburnt sites, but this was not statistically significant at the 

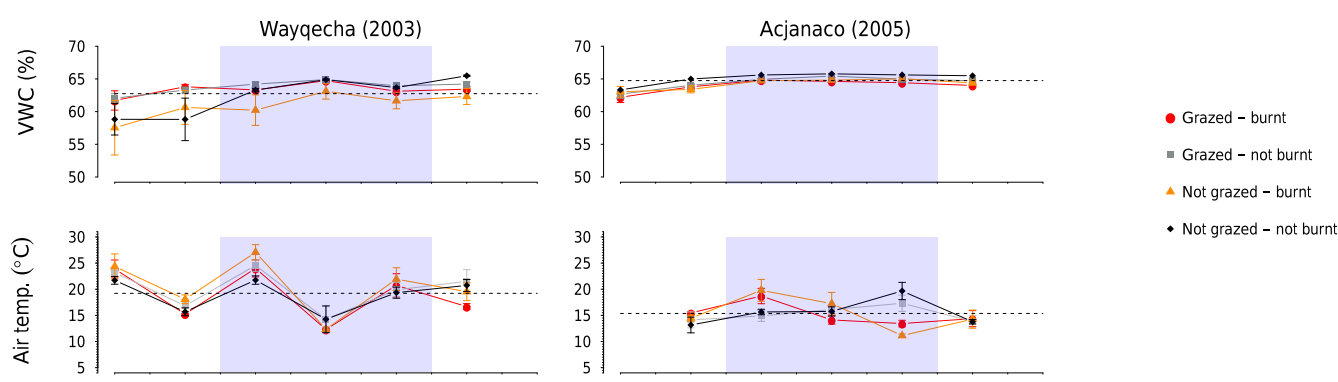

- Not grazed - not burnt
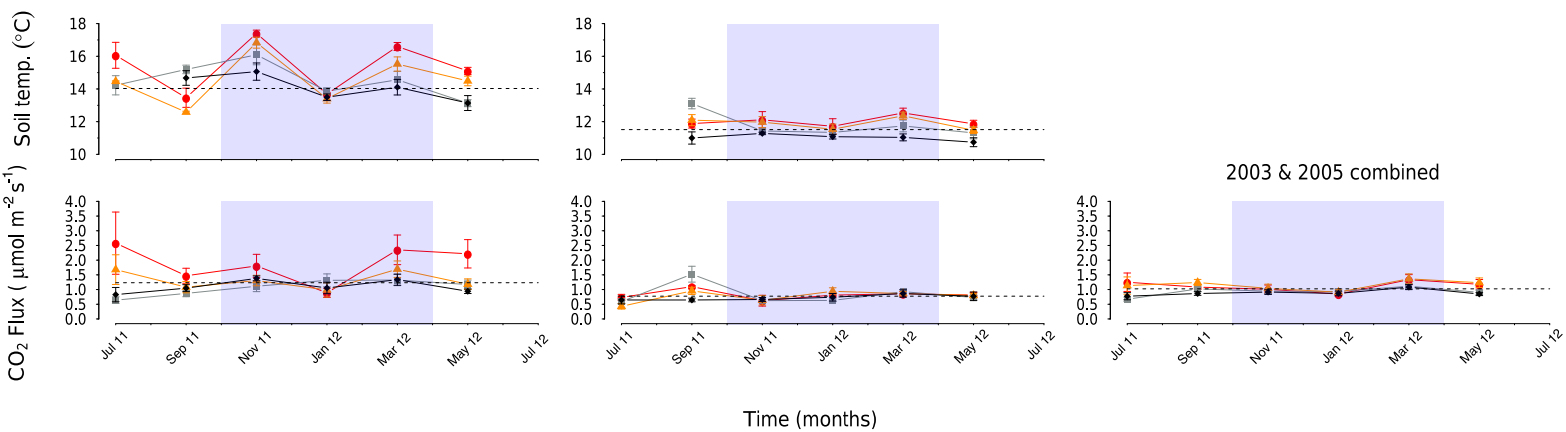

Figure 3. Monthly soil temperature $(5 \mathrm{~cm})$, air temperature, soil VWC $(0-10 \mathrm{~cm})$ and soil $\mathrm{CO}_{2}$ flux from grazed and non-grazed subplots on sites burned in 2003 (Wayqecha) and 2005 (Acjanaco) as well as adjacent non-burnt sites in the montane grassland. The graph on the right represents the mean $\mathrm{CO}_{2}$ flux of both burnt sites combined. For $\mathrm{CO}_{2}$ fluxes, each symbol is a mean of four chambers with morning and afternoon measurements combined, and standard errors $(n=8)$ are plotted as error bars. The dotted line represents the mean for that site and the blue band represents the wet season (October-March).

Table 3. Mean soil $\mathrm{C}$ content $\left(\mathrm{Mg} \mathrm{Cha}^{-1}\right)$ for each depth and total $\mathrm{C}$ stocks $(0-30$ and $0-20 \mathrm{~cm})$ on all the land management systems. Different letters down the columns within each depth represent significant differences among sites. All values are given with 1 standard error of the mean $(n=3)$.

\begin{tabular}{|c|c|c|c|c|c|c|c|}
\hline \multirow[t]{2}{*}{ Site } & \multirow[t]{2}{*}{ Land use } & \multicolumn{4}{|c|}{$\begin{array}{c}\text { Bulk C } \\
\left(\mathrm{Mg} \mathrm{Cha}^{-1}\right)\end{array}$} & \multicolumn{2}{|c|}{$\begin{array}{l}\text { Total C stock } \\
\left(\mathrm{Mg} \mathrm{Cha}^{-1}\right)\end{array}$} \\
\hline & & $0-5 \mathrm{~cm}$ & $5-10 \mathrm{~cm}$ & $10-20 \mathrm{~cm}$ & $20-30 \mathrm{~cm}$ & $0-30 \mathrm{~cm}$ & $0-20 \mathrm{~cm}$ \\
\hline Acjanaco & $\begin{array}{l}\text { Grazed-burnt } \\
\text { Not grazed-burnt } \\
\text { Grazed-not burnt } \\
\text { Not grazed-not burnt } \\
\text { Average }\end{array}$ & $\begin{array}{l}40.9 \pm 6.5^{\mathrm{a}} \\
53.5 \pm 4.5^{\mathrm{a}} \\
41.4 \pm 3.2^{\mathrm{a}} \\
40.7 \pm 8.3^{\mathrm{a}}\end{array}$ & $\begin{array}{l}31.7 \pm 4.4^{\mathrm{a}} \\
40.9 \pm 4.7^{\mathrm{a}} \\
34.7 \pm 6.6^{\mathrm{a}} \\
44.4 \pm 5.4^{\mathrm{a}}\end{array}$ & $\begin{array}{r}43.1 \pm 13.4^{\mathrm{a}} \\
76 \pm 3.7^{\mathrm{a}} \\
53.7 \pm 16^{\mathrm{a}} \\
81.4 \pm 24^{\mathrm{a}}\end{array}$ & $\begin{array}{r}57.6 \pm \\
35.4 \pm \\
44.2 \pm \\
71.6 \pm 13.4\end{array}$ & $\begin{array}{l}136 \pm 30^{\mathrm{a}} \\
182 \pm 24^{\mathrm{a}} \\
144 \pm 16^{\mathrm{a}} \\
238 \pm 33^{\mathrm{a}} \\
175 \pm 17^{\mathrm{a}}\end{array}$ & $\begin{array}{r}117 \pm 17^{\mathrm{a}} \\
170 \pm 12^{\mathrm{a}} \\
130 \pm 8^{\mathrm{a}} \\
166 \pm 22^{\mathrm{a}} \\
146 \pm 10^{\mathrm{a}}\end{array}$ \\
\hline Wayqecha & $\begin{array}{l}\text { Grazed-burnt } \\
\text { Not grazed-burnt } \\
\text { Grazed-not burnt } \\
\text { Not grazed-not burnt } \\
\text { Average }\end{array}$ & $\begin{array}{r}40 \pm 1.7^{\mathrm{a}} \\
40.3 \pm 3.3^{\mathrm{a}} \\
41.3 \pm 11.5^{\mathrm{a}} \\
38.7 \pm 5.3\end{array}$ & $\begin{aligned} 26.6 & \pm 1.6^{\mathrm{a}} \\
16 & \pm 5.7^{\mathrm{a}} \\
41.3 & \pm 9.8^{\mathrm{a}} \\
31 & \pm 3.6^{\mathrm{a}}\end{aligned}$ & $\begin{array}{r}40.8 \pm 5^{\mathrm{a}} \\
63.4 \pm 21.1^{\mathrm{a}} \\
42 \pm 5.1^{\mathrm{a}} \\
55.4 \pm 17.3^{\mathrm{a}}\end{array}$ & $\begin{array}{r}16 \pm 3.2 \\
44.4 \pm 29.5 \\
3 \pm \\
14.8 \pm 4.4\end{array}$ & $\begin{array}{l}123 \pm 10^{\mathrm{a}} \\
175 \pm 47^{\mathrm{a}} \\
126 \pm 24^{\mathrm{a}} \\
140 \pm 31^{\mathrm{a}} \\
150 \pm 15^{\mathrm{a}}\end{array}$ & $\begin{array}{r}107 \pm 8^{\mathrm{a}} \\
131 \pm 18^{\mathrm{a}} \\
125 \pm 25^{\mathrm{a}} \\
125 \pm 26^{\mathrm{a}} \\
122 \pm 9^{\mathrm{a}}\end{array}$ \\
\hline $\begin{array}{l}\text { Acjanaco + } \\
\text { Wayqecha }\end{array}$ & $\begin{array}{l}\text { Grazed-burnt } \\
\text { Not grazed-burnt } \\
\text { Grazed-not burnt } \\
\text { Not grazed-not burnt }\end{array}$ & $\begin{array}{l}40 \pm 3^{\mathrm{a}} \\
47 \pm 4^{\mathrm{a}} \\
41 \pm 5^{\mathrm{a}} \\
40 \pm 4^{\mathrm{a}}\end{array}$ & $\begin{array}{l}30 \pm 2^{\mathrm{a}} \\
34 \pm 5^{\mathrm{a}} \\
38 \pm 5^{\mathrm{a}} \\
38 \pm 4^{\mathrm{a}}\end{array}$ & $\begin{array}{r}42 \pm 6^{\mathrm{a}} \\
70 \pm 10^{\mathrm{a}} \\
48 \pm 8^{\mathrm{a}} \\
68 \pm 14^{\mathrm{a}}\end{array}$ & $\begin{array}{l}26 \pm 11^{\mathrm{a}} \\
42 \pm 21^{\mathrm{a}} \\
24 \pm 21^{\mathrm{a}} \\
43 \pm 14^{\mathrm{a}}\end{array}$ & $\begin{array}{l}130 \pm 20^{\mathrm{a}} \\
179 \pm 36^{\mathrm{a}} \\
135 \pm 20^{\mathrm{a}} \\
189 \pm 32^{\mathrm{a}}\end{array}$ & $\begin{array}{l}112 \pm 12^{\mathrm{a}} \\
151 \pm 15^{\mathrm{a}} \\
127 \pm 16^{\mathrm{a}} \\
146 \pm 24^{\mathrm{a}}\end{array}$ \\
\hline
\end{tabular}

$P<0.05$ level. On average, Acjanaco (2003) had higher C stocks (175 $\pm 17 \mathrm{Mg} \mathrm{Cha}^{-1}$ ) compared to Wayqecha (2005) $\left(150 \pm 15 \mathrm{Mg} \mathrm{Cha}^{-1}\right)$.
The pooled dataset demonstrated that these soils have a notably large free LF $(\sim 20 \%)$. When looking at the different treatments and averaging the data across the soil profile $(0-30 \mathrm{~cm})$, burning and grazing significantly reduced the pro- 

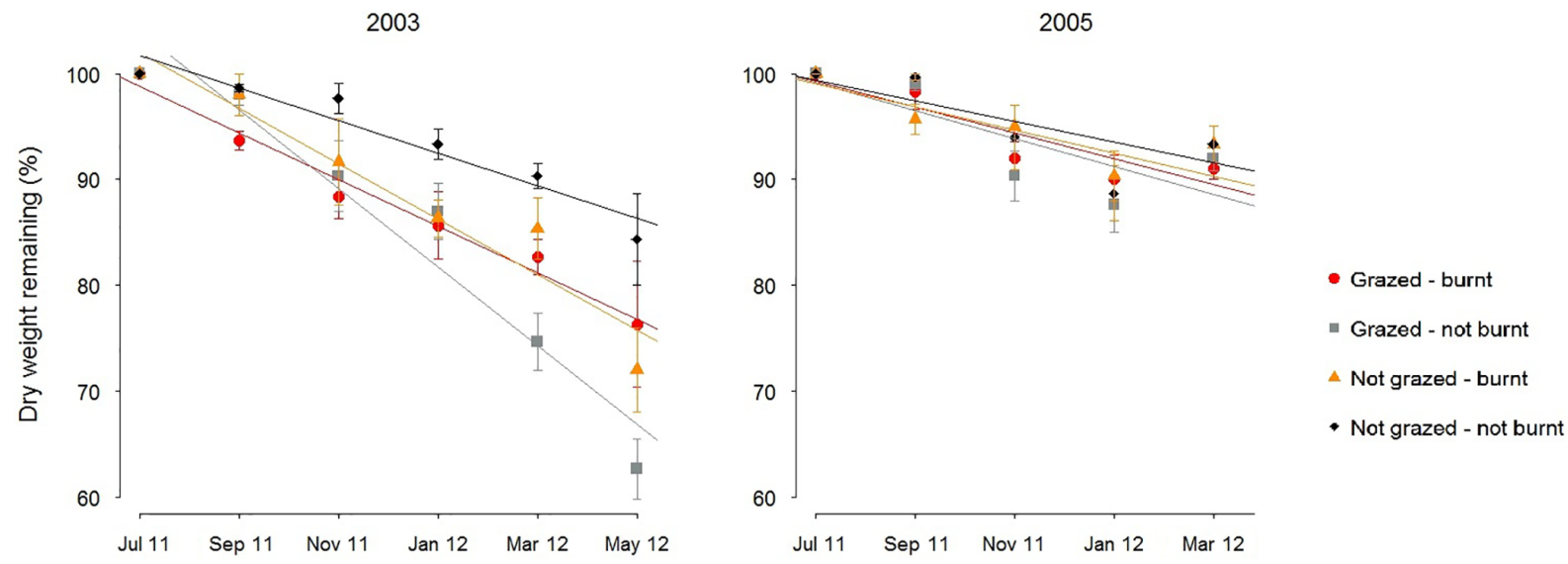

Time (months)

Figure 4. Mass losses $(\%)$ of sticks from the decomposition experiment $(n=3)$ on two burnt sites (left, 2003 is Wayqecha; right, 2005 is Acjanaco) with grazed subplots and control plots.

- Free LF $\square$ Occluded LF $\square$ Heavy F
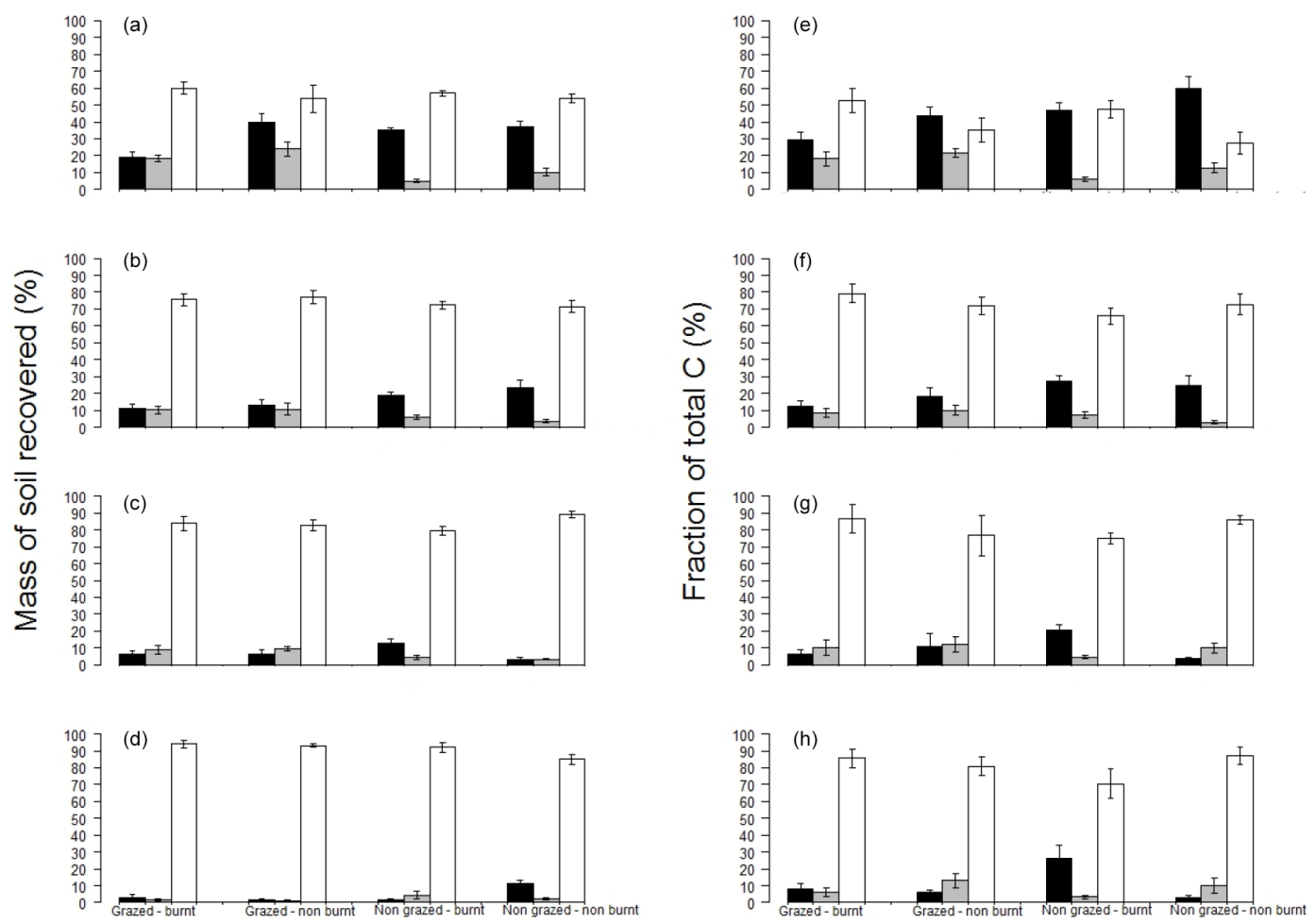

Figure 5. Mass of soil recovered in the three density fractions (\%) on the four left bar plots and the proportion of total $\mathrm{C}$ residing in the three density fractions $(\%)$ on the four right bar plots for the different land uses $(\mathbf{a}=0-5, \mathbf{b}=5-10, \mathbf{c}=10-20, \mathbf{d}=20-30 \mathrm{~cm})$. Error bars indicate 1 standard error of the mean $(n=6)$.

portion of C in the free LF (Table 4). The free LF in the control soils made $20 \%$ of the bulk soil mass and $30 \%$ of the soil C content compared to the burnt-grazed soils, which had the smallest recovery of free LF $(10 \%)$ and had significantly lower C content (14\%). However, when analysing the depths individually, there was only a significant loss of $\mathrm{C}$ in the free LF at $0-5$ and $10-20 \mathrm{~cm}$ depth, with a reduction of $\sim 16 \%$ (Fig. 5). When analysing the two sites separately, the burnt- 
Table 4. Mean mass recovery of density fractions and proportion of total $\mathrm{C}$ residing in the three density fractions (\%) from the total soil profile $(0-30 \mathrm{~cm})$. Different letters down the columns represent significant differences.

\begin{tabular}{|c|c|c|c|c|c|c|}
\hline & \multicolumn{2}{|c|}{ Free LF } & \multicolumn{2}{|c|}{ Occluded LF } & \multicolumn{2}{|c|}{ Heavy F } \\
\hline & $\begin{array}{r}\text { Fraction of } \\
\text { total } \mathrm{C} \\
(\%)\end{array}$ & $\begin{array}{r}\text { Mass of soil } \\
\text { recovered } \\
(\%)\end{array}$ & $\begin{array}{r}\text { Fraction of } \\
\text { total C } \\
(\%)\end{array}$ & $\begin{array}{r}\text { Mass of soil } \\
\text { recovered } \\
(\%)\end{array}$ & $\begin{array}{r}\text { Fraction of } \\
\text { total C } \\
(\%)\end{array}$ & $\begin{array}{r}\text { Mass of soil } \\
\text { recovered } \\
(\%)\end{array}$ \\
\hline Grazed-burnt & $14.0 \pm 5.3^{\mathrm{a}}$ & $9.9 \pm 3.6^{\mathrm{a}}$ & $10.8 \pm 2.6^{\mathrm{ab}}$ & $9.8 \pm 3.4^{\mathrm{ab}}$ & $76.0 \pm 8.0^{\mathrm{a}}$ & $78.4 \pm 7.2^{\mathrm{a}}$ \\
\hline Grazed-not burnt & $22.7 \pm 13.3^{\mathrm{ab}}$ & $16.2 \pm 8.5^{\mathrm{a}}$ & $8.9 \pm 2.1^{b c}$ & $5.3 \pm 1.6^{b c}$ & $68.3 \pm 14.0^{\mathrm{a}}$ & $76.7 \pm 8.1^{\mathrm{a}}$ \\
\hline Not grazed-burnt & $19.7 \pm 8.3^{\mathrm{ab}}$ & $15.1 \pm 8.5^{\mathrm{a}}$ & $14.2 \pm 2.5^{\mathrm{a}}$ & $11.3 \pm 4.7^{\mathrm{a}}$ & $66.1 \pm 10.5^{\mathrm{a}}$ & $76.6 \pm 8.3^{\mathrm{a}}$ \\
\hline Not grazed-not burnt & $30.0 \pm 5.7^{\mathrm{a}}$ & $19.5 \pm 5.5^{\mathrm{a}}$ & $5.2 \pm 0.8^{\mathrm{c}}$ & $4.3 \pm 0.7^{\mathrm{c}}$ & $64.7 \pm 6.1^{\mathrm{a}}$ & $69.7 \pm 5.8^{\mathrm{a}}$ \\
\hline
\end{tabular}

grazed soils at Wayqecha had a significantly smaller proportion of $\mathrm{C}$ in the free $\mathrm{LF}$ at $0-5 \mathrm{~cm}(p$-value $=0.002)$, whereas at Acjanaco there were no significant differences among the land uses.

The occluded LF increased significantly after burning. The burnt soils had a much higher proportion of $\mathrm{C}$ in the occluded LF (12\%) compared to the not-burnt soils (7\%) when the data were pooled from across different soil depths $(0-30 \mathrm{~cm})$ for the two sites. When the data were disaggregated by site, we found that burning produced site-specific effects on the occluded LF in different soil depths. For example, at Wayqecha the proportion of $\mathrm{C}$ in the occluded LF was higher on the burnt soils when looking at the whole profile $(0-30 \mathrm{~cm})$, but there were no significant differences among the separate soil layers. In contrast, at Acjanaco the burnt soils had a significantly higher proportion of $\mathrm{C}$ in the occluded LF in the uppermost layer $(0-5 \mathrm{~cm})$ (grazedburnt $24.7 \pm 7.1$ and not grazed-burnt $23.5 \pm 9.5 \%$ ) compared to non-burnt soils (grazed-not burnt $=10.3 \pm 4.6$ and not grazed-not burnt $=6.1 \pm 2.4 \%$ ).

The largest mass of soil $\mathrm{C}$ recovered was in the heavy $\mathrm{F}(\sim 70 \%)$. Overall, there were no significant differences among the treatments when the data were pooled for the two sites and across all four depths $(0-30 \mathrm{~cm})$. However, when the data were disaggregated by site, we found site-specific treatment effects on the heavy $\mathrm{F}$ that varied depending on soil depth. For example, in Wayqecha the grazed-burnt plot had a significantly higher portion of $\mathrm{C}$ in the heavy $\mathrm{F}$ in the $0-5 \mathrm{~cm}$ soil layer $(67.7 \pm 4.8 \%)$ compared to the control plot $(48.6 \pm 3.7 \%)$. We also observed a significantly lower proportion of $\mathrm{C}$ in the grazed-not-burnt plot $(19.2 \pm 12.2 \%)$ in the $0-5 \mathrm{~cm}$ soil layer compared to the other treatments. In contrast, at Acjanaco there were no significant differences measured among the treatments.

\section{Discussion}

\subsection{Soil respiration and decomposition rates}

In this study, soil $\mathrm{CO}_{2}$ fluxes ranged from 0.72 to $1.88 \mu \mathrm{mol} \mathrm{m}^{-2} \mathrm{~s}^{-1}\left(2.73-7.14 \mathrm{Mg} \mathrm{Cha}^{-1} \mathrm{yr}^{-1}\right)^{1}$, which is in the lower range $\left(0.7-14.8 \mathrm{Mg} \mathrm{Cha}^{-1} \mathrm{yr}^{-1}\right)$ of other highelevation montane grassland studies (Cao et al., 2004; Geng et al., 2012; Muñoz et al., 2013; Fu et al., 2014) and corroborates prior work by Oliveras et al. (2014) $(3.4-3.7 \mathrm{Mg}$ $\left.\mathrm{Cha}^{-1} \mathrm{yr}^{-1}\right)$. The absence of a seasonal trend in temperature and moisture has also been noted in other studies from the same region (Girardin et al., 2010; Teh et al., 2014).

Higher soil respiration and faster decomposition rates were consistently measured on the plots at Wayqecha (burnt in 2003) than at Acjanaco (2005), which is in keeping with Oliveras et al. (2014). These site-specific differences may not be a reflection of the age of burning but rather of Acjanaco being at a slightly higher elevation and on average $4{ }^{\circ} \mathrm{C}$ cooler. Despite the variance in mean annual temperature, the two sites both showed a positive correlation between temperature and soil respiration. Interestingly, though, the decomposition rates at Acjanaco correlated with the $\mathrm{CO}_{2}$ fluxes, suggesting that decay was a good predictor of $\mathrm{CO}_{2}$ flux. This was in contrast to the lower elevation site in Wayqecha, where $\mathrm{CO}_{2}$ fluxes did not correlate with decomposition rates, implying that autotrophic respiration or other environmental factors may have had a stronger influence on soil respiration.

Burning alone or grazing alone enhanced soil respiration and decomposition rates when these land management practices were considered separately, with soil temperature identified as the main environmental driver in each of these treatment types. However, when plots had been exposed to both burning and grazing together, soil temperature no longer correlated well with soil respiration. The combination of burning and grazing also produced higher soil respiration rates than the two treatments independently. While this pattern has been identified before in other studies (Ward et al., 2007), the

\footnotetext{
${ }^{1}$ The units have been converted to enable comparison to other studies but, due to limited frequency of sampling in this study, this may not produce sufficient data to reliably provide yearly emissions.
} 
drivers of this increase are less well understood, and the influence of grazing and burning have been known to have confounding effects (Michelsen et al., 2004). One potential explanation is that burning and grazing together act synergistically and may obscure the influence of temperature due to the action of other complex processes or drivers, such as changes in plant $\mathrm{C}$ allocation and autotrophic respiration following the effects of the two combined disturbances. For example, studies have found that, when foliage is cut, photosynthate and other resources are allocated to the growth of new shoots rather than to the roots (Schmitt et al., 2013), causing a decline in root respiration (Garcia-Oliva et al., 1999). The resulting root death may enhance heterotrophic microbial activity, counteracting the effects of reduced root respiration.

Alternatively, burning can cause significant losses of $\mathrm{N}$ due to combustion, and grasses may compensate for increased $\mathrm{N}$ limitation by increasing their allocation to roots, thereby increasing root respiration and potentially promoting enhanced belowground $\mathrm{C}$ cycling (Johnson and Matchett, 2001). Some evidence was found for this type of response in prior work; Oliveras et al. (2014) found higher belowand aboveground $\mathrm{C}$ stocks in undisturbed soils. While overall NPP was higher on undisturbed sites, NPP belowground was greater with grazing and fire, suggesting a shift in plant allocation patterns after these disturbances.

\subsection{Belowground C stocks}

Overall, large total SOC stocks were measured in these montane grasslands $\left(123-238 \mathrm{Mg} \mathrm{Cha}^{-1}\right)$, which is in keeping with other high-elevation grassland studies and are probably attributable to low temperatures and wet conditions causing slow mineralization of SOM and turnover rates. For example, in the Qinghai-Tibet Plateau grasslands and páramo grasslands of the Colombian, Ecuadorian and Peruvian Andes, total SOC stocks can range between 80 and $250 \mathrm{Mg}$ $\mathrm{Cha}^{-1}$ (Hofstede, 1995; Zimmermann et al., 2010; Farley et al., 2012; Li et al., 2013; Muñoz et al., 2013; Oliveras et al., 2014b).

Soil C stocks were higher at Acjanaco than at Wayqecha. This is in agreement with Oliveras et al. (2014), although the Acjanaco sites in this previous study were higher (253 compared to $175 \mathrm{Mg} \mathrm{Cha}^{-1}$ reported here), perhaps reflecting within-site spatial heterogeneity. There was no significant effect of either burning or grazing but grazing had a more negative effect than burning on the total soil $\mathrm{C}$ stocks. This negligible effect of burning may be a consequence of lowintensity fires, fire-resilient grasses and potentially low fuel loads at the time of burning (Knicker, 2007). Grassland fires on slopes can move very quickly, so, even when intense, the transfer of heat to the soil is less damaging due to low residence times (Rollins et al., 1993). As a result, surface temperatures do not typically exceed 100 or $50^{\circ} \mathrm{C}$ at $5 \mathrm{~cm}$ depth (Campbell et al., 1995), and organic matter can only be fully volatilized between 200 and $315^{\circ} \mathrm{C}$ (Knicker, 2007). Even if the soils were dry at the time of burning, which is possible during the dry season, then belowground temperatures would rise very slowly because of the insulating properties of air-filled pores, which curtail heat transfer belowground (Neary et al., 1999).

Grazing, on the other hand, caused a decrease in the total SOC content compared with burning, although this numerical difference was not statistically significant at the $P<0.05$ level. One explanation is that the grazing pressure in these sites may have been below the threshold required to cause severe degradation, supporting previous studies in the Peruvian Andes, where they also found no significant effect of grazing or burning on total SOC stocks (Gibbon et al., 2010; Oliveras et al., 2014b).

In this study, the free LF was larger than in other tropical systems (30\% of total soil C). By comparison, studies in Ecuador, Brazil and Puerto Rico found the free LF ranged from only $4-12 \%$ of total soil C content (Paul et al., 2008; Marin-Spiotta et al., 2009; Potes et al., 2012). However, it is difficult to compare the results of this study to other tropical fractionation studies because, in general, most field sites are in tropical lowland pastures where soil $\mathrm{C}$ stocks tend to be lower. When comparing to other high-elevational studies, for example, in permafrost meadow ecosystems in the Tibetan Plateau, Qinghai Province, results are similar, with the free LF making up $27 \%$ of the total soil C stocks (Dörfer et al., 2013). Comparisons are also further complicated by land management history and methodological differences. For example, in a review of 22 grassland studies, the average fraction of soil organic $\mathrm{C}$ in the free $\mathrm{LF}$ was $13.9 \%$, but the range was between 1.8 and $55 \%$ (Gregorich et al., 2006).

Overall, grazing significantly reduced the free LF. As grazing is known for reducing aboveground biomass (Johnson and Matchett, 2001; Gibbon et al., 2010), a lower incorporation of detritus into the soil is not surprising and has been observed in other grazing studies (Figueiredo et al., 2010; Cao et al., 2013). While there was a significant decrease in the free LF, there was no significant change to the total SOC. Due to the dynamic nature and sensitive response of this pool to land management or land use change, other studies have also measured reductions in the free LF, while the total SOC content appears to be unchanged (Leifeld and Kögel-Knabner, 2005; Zimmermann et al., 2007; Marín-Spiotta et al., 2008; Cao et al., 2013).

The effects of grazing on the free LF were most noticeable when grazing and burning occurred together, in which case the free LF showed the most pronounced declines. This was especially evident on one of the sites (Wayqecha) in the top soil layer $(0-5 \mathrm{~cm})$ and mid-soil layer $(10-20 \mathrm{~cm})$ and could be attributed to site-specific differences, such as warmer temperatures causing higher turnover rates. To our knowledge there are no other studies assessing the impact of grazing and burning on soil $\mathrm{C}$ fractions in high-altitude tropical grasslands. However, studies focusing on burning in grasslands have found a decrease in the free LF with burning history, 
due to the resulting decrease in litter inputs to the soil (Fynn et al., 2003; Potes et al., 2012).

When measuring the soil organic pools, the long-term effects of land use can be gained by relatively short-term experiments because burning, in theory, could have a relatively immediate impact on all the pools of carbon. In this study, the significant increase in the occluded LF in the burnt soils may be the results of charcoal particles (from burning) becoming incorporated into the occluded LF. Charcoal, because of its low density, tends to reside in the lighter fractions (Cadisch et al., 1996; Glaser et al., 2000; Sollins et al., 2006), despite its recalcitrance. However, because the fires took place almost 10 years ago, the charcoal may no longer be present in the free LF and could have become occluded into soil microaggregates due to its high sorptive capacity (Knicker, 2007; Qayyum et al., 2014). This has been observed in different soil types, such as Haplic Luvisols and Andosols (Golchin et al., 1997; Brodowski et al., 2006), and, once incorporated into micro-aggregates, charcoal can be maintained for centuries after fire (Zackrisson et al., 1996).

\section{Conclusions}

This study highlights the complexities of how land management can affect soil $\mathrm{C}$ dynamics in montane tropical grasslands. The results suggest that montane grasslands are resilient to soil $\mathrm{C}$ losses under moderate intensity land use. Total C stocks appeared unaffected by burning and grazing, although a change was observed in the distribution of soil $\mathrm{C}$ across different soil $\mathrm{C}$ fractions, with burning leading to a significant reduction in the free LF pool and an enhancement of the occluded LF pool. Most specifically, our study shows that land management affected the magnitude and drivers of soil respiration and decomposition. Individually, burning and grazing alone increased soil $\mathrm{CO}_{2}$ fluxes, which was apparently driven by shifts in soil temperature. However, the combined effect of burning and grazing together interacted synergistically, leading to enhanced soil respiration rates, while simultaneously obscuring the role of temperature and other environmental drivers, potentially due to changes in patterns of plant $\mathrm{C}$ and $\mathrm{N}$ allocations.

Data availability. The data set related to this article is available at the NERC Environmental Information Data Centre: https://doi.org/ 10.5285/3813aef3-71cc-49e6-ba21-495a43363001.

Author contributions. VO designed the study, conducted the fieldwork, performed the statistical data analysis and wrote the manuscript. IO designed the study, provided supervision and contributed to writing the manuscript. JK and RL conducted the fieldwork and laboratory analysis. YAT obtained funding for the work, provided supervision for the whole study and contributed to writing the manuscript.
Competing interests. The authors declare that they have no conflict of interest.

Acknowledgements. The authors wish to thank the Manu National Park forest rangers for allowing us to use their facilities and the field technicians for their assistance. We also thank the Amazon Basin Conservation Association for institutional support. This material is based upon work supported by the UK Natural Environment Council under joint grant references NE/H006583, $\mathrm{NE} / \mathrm{H} 007849$ and NE/H006753. This publication is a contribution from the Scottish Alliance for Geoscience, Environment and Society (http://www.sages.ac.uk). Imma Oliveras was supported with a NERC grant NE/G006385/1.

Edited by: Edzo Veldkamp

Reviewed by: two anonymous referees

\section{References}

Allison, S.: A trait-based approach for modelling microbial litter decomposition, Ecol. Lett., 15, 1058-1070, 2012.

Bates, D., Maechler, M., Bolker, B., and Walker, S.: lme4: Linear mixed-effects models using Eigen and S4, R Package Version, 1, 1-23, 2014.

Bayer, C., Martin-Neto, L., Mielniczuk, J., Pillon, C., and Sangoi, L.: Changes in soil organic matter fractions under subtropical no-till cropping systems, Soil Sci. Soc. Am. J., 65, 1473-1478, 2001.

Bol, R., Poirier, N., Balesdent, J., and Gleixner, G.: Molecular turnover time of soil organic matter in particle-size fractions of an arable soil, Rapid Commun. Mass Sp., 23, 2551-2558, 2009.

Brodowski, S., John, B., Flessa, H., and Amelung, W.: Aggregateoccluded black carbon in soil, Eur. J. Soil Sci., 57, 539-546, 2006.

Brown, S. and Lugo, A. E.: The storage and production of organic matter in tropical forests and their role in the global carbon cycle, Biotropica, 161-87, 1982.

Cadisch, G., Imhof, H., Urquiaga, S., Boddey, R., and Giller, K. Carbon turnover $\left(\delta^{13} \mathrm{C}\right)$ and nitrogen mineralization potential of particulate light soil organic matter after rainforest clearing, Soil Biol. Biochem., 28, 1555-1567, 1996.

Campbell, G. S., Jungbauer Jr. J., Bristow, K. L., and Hungerford, R. D.: Soil temperature and water content beneath a surface fire, Soil Sci., 159, 363-374, 1995.

Cao, G., Tang, Y., Mo, W., Li, Y., and Zhao, X.: Grazing intensity alters soil respiration in an alpine meadow on the Tibetan plateau, Soil Biol. Biochem., 36, 237-243, 2004.

Cao, J., Wang, X., Sun, X., Zhang, L., and Tian, Y.: Effects of grazing intensity on soil labile organic carbon fractions in a desert steppe area in Inner Mongolia, Springer Plus, 2, https://doi.org/10.1186/2193-1801-2-S1-S1, 2013.

Carlotto, V., Gil, W., Cardenas, J., and Chavez, R.: Mapa Geologico del Cuadrangula de Calca (27-s) Republica del Peru: Ministerio de engergia y minas Instituto geologico minero y metalurgico (INGEMMET), 1996. 
Christensen, B. T.: Physical fractionation of soil and structural and functional complexity in organic matter turnover, Eur. J. Soil Sci., 52, 345-353, 2001

Cochrane, M. A. and Ryan, K. C.: Fire and fire ecology: Concepts and principles, Tropical Fire Ecology, Springer, 25-62, 2009.

Coleman, K. and Jenkinson, D.: RothC-26.3 - A Model for the turnover of carbon in soil, Evaluation of Soil Organic Matter Models, Springer, 237-46, 1996.

Conant, R. T., Ogle, S. M., Paul, E. A., and Paustian, K.: Measuring and monitoring soil organic carbon stocks in agricultural lands for climate mitigation, Front. Ecol. Environ., 9, 169-173, 2011.

de Figueiredo, C. C., Resck, D. V. S., and Carneiro, M. A. C.: Labile and stable fractions of soil organic matter under management systems and native cerrado, Rev. Bras. Ciênc. Solo, 34, 907-916, 2010.

Derenne, S. and Largeau, C.: A review of some important families of refractory macromolecules: Composition, origin, and fate in soils and sediments, Soil Sci., 166, 833-847, 2001.

Diem, T., Morley, N. J., Ccahuana, A. J., Huaraca Quispe, L. P., Baggs, E. M., Meir, P., Richards, M. I. A., Smith, P., and Teh, Y. A.: Complex controls on nitrous oxide flux across a long elevation gradient in the tropical Peruvian Andes, Biogeosciences Discuss., https://doi.org/10.5194/bg-2017-107, in review, 2017.

Di Pasquale, G., Marziano, M., Impagliazzo, S., Lubritto, C., De Natale, A., and Bader, M. Y.: The Holocene treeline in the northern Andes (Ecuador): First evidence from soil charcoal, Paleoecol. Rec. Mt. Reg., 259, 17-34, 2008.

Dörfer, C., Kühn, P., Baumann, F., He, J.-S., and Scholten, T.: Soil organic carbon pools and stocks in permafrostaffected soils on the Tibetan Plateau, PLoS One, 8, e57024, https://doi.org/10.1371/journal.pone.0057024, 2013.

Falloon, P. D. and Smith, P.: Modelling refractory soil organic matter, Biol. Fertil. Soils, 30, 388-398, 2000.

Farley, K. A., Bremer, L. L., Harden, C. P., and Hartsig, J.: Changes in carbon storage under alternative land uses in biodiverse Andean grasslands: implications for payment for ecosystem services, 6, 21-27, 2012.

Feeley, K. J. and Silman, M. R.: Land-use and climate change effects on population size and extinction risk of Andean plants, Glob. Change Biol., 16, 3215-322, 2010.

Fu, G., Zhang, X., Yu, C., Shi, P., Zhou, Y., Li, Y., Yang, P., and Shen, Z.: Response of soil respiration to grazing in an alpine meadow at three elevations in Tibet, Sci. World J., 9 pp., 2014.

Fynn, R. W. S., Haynes, R. J., and O'Connor, T. G.: Burning causes long-term changes in soil organic matter content of a South African grassland, Soil Biol. Biochem., 35, 677-687, 2003.

Garcia-Oliva, F., Sanford, R. L., and Kelly, E.: Effects of slash-andburn management on soil aggregate organic $\mathrm{C}$ and $\mathrm{N}$ in a tropical deciduous forest, Geoderma, 88, 1-12, 1999.

Geng, Y., Wang, Y., Yang, K., Wang, S., Zeng, H., Baumann, F., Kuehn, P., Scholten, T., and He, J.-S.: Soil respiration in Tibetan alpine grasslands: belowground biomass and soil moisture, but not soil temperature, best explain the large-scale patterns, PloS One, 7, e34968, https://doi.org/10.1371/journal.pone.0034968, 2012.

Gibbon, A., Silman, M. R., Malhi, Y., Fisher, J. B., Meir, P., Zimmermann, M., Dargie, G. C., Farfan, W. R., and Garcia, K. C.: Ecosystem Carbon Storage Across the Grassland-Forest Transi- tion in the High Andes of Manu National Park, Peru, Ecosystems, 13, 1097-1111, 2010.

Girardin, C. A. J., Malhi, Y., Aragao, L., Mamani, M., Huaraca Huasco, W., Durand, L., Feeley, K., Rapp, J., Silva-Espejo, J., and Silman, M.: Net primary productivity allocation and cycling of carbon along a tropical forest elevational transect in the Peruvian Andes, Glob. Change Biol., 16, 3176-3192, 2010.

Glaser, B., Balashov, E., Haumaier, L., Guggenberger, G., and Zech, W.: Black carbon in density fractions of anthropogenic soils of the Brazilian Amazon region, Org. Geochem., 31, 669-678, 2000.

Golchin, A., Clarke, P., Baldock, J. A., Higashi, T., Skjemstad, J. O., and Oades, J. M.: The effects of vegetation and burning on the chemical composition of soil organic matter in a volcanic ash soil as shown by ${ }^{13} \mathrm{C}$ NMR spectroscopy, I. Whole soil and humic acid fraction, Geoderma, 76, 155-174, 1997.

Gregorich, E. G., Beare, M. H., and McKim, U. F., and Skjemstad, J. O.: Chemical and Biological Characteristics of Physically Uncomplexed Organic Matter, Soil Sci. Soc. Am. J., 70, 975-985, 2006.

Hofstede, R. G.: The effects of grazing and burning on soil and plant nutrient concentrations in Colombian páramo grasslands, Plant Soil, 173, 111-132, 1995.

Islam, K. R. and Weil, R.: Land use effects on soil quality in a tropical forest ecosystem of Bangladesh, Agr. Ecosyst. Environ., 79, 9-16, 2000.

Johnson, L. C. and Matchett, J. R.: Fire and grazing regulate belowground processes in tallgrass prairie, Ecology, 82, 3377-3389, 2001.

Kennedy, A. and Papendick, R.: Microbial characteristics of soil quality, J. Soil Water Conserv., 50, 243-248, 1995.

Kirschbaum, M. U.: The temperature dependence of soil organic matter decomposition, and the effect of global warming on soil organic C storage, Soil Biol. Biochem., 27, 753-760, 1995.

Klute, A. (Ed.): Methods of Soil Analysis: Part 1 - Physical and Mineralogical Methods, Madison, WI: Soil Science Society of America, American Society of Agronomy, 1986.

Knicker, H.: How does fire affect the nature and stability of soil organic nitrogen and carbon? A review, Biogeochemistry, 85, 91118, 2007.

Krull, E. S., Baldock, J. A., and Skjemstad, J. O.: Importance of mechanisms and processes of the stabilisation of soil organic matter for modelling carbon turnover, Funct. Plant Biol., 30, 207-222, 2003.

Lal, R.: Soil carbon sequestration to mitigate climate change, Geoderma, 123, 1-22, 2004.

Leifeld, J. and Kögel-Knabner, I.: Soil organic matter fractions as early indicators for carbon stock changes under different landuse?, Geoderma, 124, 143-155, 2005.

Li, Y., Dong, S., Wen, L., Wang, X., and Wu, Y.: The effects of fencing on carbon stocks in the degraded alpine grasslands of the Qinghai-Tibetan Plateau, J. Environ. Manage., 128, 393-399, 2013.

Luteyn, J. L.: Páramo: An Andean Ecosystem under Human Influence, London, San Diego, Academic Press, 282 pp., 1992.

Marin-Spiotta, E., Silver, W. L., Swanston, C. W., and Osterag, R.: Soil organic matter dynamics during 80 years of reforestation of tropical pastures, Glob. Change Biol., 15, 1584-1597, 2009. 
Marín-Spiotta, E., Swanston, C. W., Torn, M. S., Silver, W. L., and Burton, S. D.: Chemical and mineral control of soil carbon turnover in abandoned tropical pastures, Geoderma, 143, 49-62, 2008.

Michelsen, A., Andersson, M., Jensen, M., Kjøller, A., and Gashew, M.: Carbon stocks, soil respiration and microbial biomass in fireprone tropical grassland, woodland and forest ecosystems, Soil Biol. Biochem., 36, 1707-1017, 2004.

Mueller, C. W. and Koegel-Knabner, I.: Soil organic carbon stocks, distribution, and composition affected by historic land use changes on adjacent sites, Biol. Fertil. Soils, 45, 347-359, 2009.

Muñoz, M., Faz, A., and Zornoza, R.: Carbon stocks and dynamics in grazing highlands from the Andean Plateau, Catena, 104, 136143, 2013.

Neary, D. G., Klopatek, C. C., DeBano, L. F., and Ffolliott, P. F.: Fire effects on belowground sustainability: a review and synthesis, Forest Ecol. Manag., 122, 51-71, 1999.

Ojima, D. S., Schimel, D. S., Parton, W. J., and Owensby, C. E.: Long- and short-term effects of fire on nitrogen cycling in tallgrass prairie, Biogeochemistry, 24, 67-84, 1994.

Oliveras, I., van der Eynden, M., Malhi, Y., Cahuana, N., Menor, C., Zamora, F., and Haugaasen, T.: Grass allometry and estimation of above-ground biomass in tropical alpine tussock grasslands, Austral. Ecol., 39, 408-415, 2014a.

Oliveras, I., Girardin, C., Doughty, C., Cahuana, N., Arenas, C., Oliver, V., Huasco, W. H., and Malhi, Y.: Andean grasslands are as productive as tropical cloud forests, Environ. Res. Lett., 9, 115011, https://doi.org/10.1088/1748-9326/9/11/115011, 2014b.

Paul, S., Veldkamp, E., and Flessa, H.: Soil organic carbon in density fractions of tropical soils under forest-pasture-secondary forest land use changes, Eur. J. Soil Sci., 59, 359-371, 2008.

Pedersen, A. R., Petersen, S. O., and Schelde, K.: A comprehensive approach to soil-atmosphere trace-gas flux estimation with static chambers, Eur. J. Soil Sci., 61, 888-902, 2010.

Petrokofsky, G., Kanamaru, H., Achard, F., Goetz, S. J., Joosten, H., Holmgren, P., Lehtonen, A., Menton, M. C., Pullin, A. S., and Wattenbach, M.: Comparison of methods for measuring and assessing carbon stocks and carbon stock changes in terrestrial carbon pools, How do the accuracy and precision of current methods compare? A systematic review protocol, Environmental Evidence, 1, 2012.

Poeplau, C. and Don, A.: Sensitivity of soil organic carbon stocks and fractions to different land-use changes across Europe, Geoderma, 192, 189-201, 2013.

Potes, M. da L., Dick, D. P., Santana, G. S., Tomazi, M., and Bayer, C.: Soil organic matter in fire-affected pastures and in an Araucaria forest in South-Brazilian Leptosols, Pesqui. Agropecu. Bras., 47, 707-715, 2012.

Qayyum, M., Steffens, D., Reisenauer, H., and Schubert, S.: Biochars influence differential distribution and chemical composition of soil organic matter, Plant. Soil Env., 60, 337-343, 2014.

Raich, J. and Schlesinger, W. H.: The global carbon dioxide flux in soil respiration and its relationship to vegetation and climate, Tellus B, 44, 81-99, 1992.

Ramsay, P. M.: The páramo vegetation of Ecuador: the community ecology, dynamics and productivity of tropical grasslands in the Andes, PhD thesis, Prifysgol Bangor University, 1992.
Rollins, M. S., Cohen, A. D., and Durig, J. R.: Effects of fires on the chemical and petrographic composition of peat in the Snuggedy Swamp, South Carolina, Int. J. Coal. Geol., 22, 101-117, 1993.

Sarmiento, F. O. and Frolich, L. M.: Andean Cloud Forest Tree Lines, Mt. Res. Dev., 22, 278-287, 2002.

Schmidt, M. W. I., Torn, M. S., Abiven, S., Dittmar, T., Guggenberger, G., Janssens, I. A., Kleber, M., Kogel-Knabner, I., Lehmann, J., Manning, D. A. C., Nannipieri, P., Rasse, D. P., Weiner, S., and Trumbore, S. E.: Persistence of soil organic matter as an ecosystem property, Nature, 478, 49-56, 2011.

Schmitt, A., Pausch, J., and Kuzyakov, Y.: Effect of clipping and shading on $\mathrm{C}$ allocation and fluxes in soil under ryegrass and alfalfa estimated by ${ }^{14} \mathrm{C}$ labelling, Appl. Soil Ecol., 64, 228-236, 2013.

Six, J., Conant, R., Paul, E. A., and Paustian, K.: Stabilization mechanisms of soil organic matter: implications for C-saturation of soils, Plant Soil, 241, 155-176, 2002.

Six, J.: Organic matter turnover, Encycl Soil Sci Marcel Dekker NY, 936-942, 2002.

Skjemstad, J., Spouncer, L., Cowie, B., and Swift, R.: Calibration of the Rothamsted organic carbon turnover model (RothC ver. 26.3), using measurable soil organic carbon pools, Soil Res., 42, 79-88, 2004.

Sollins, P., Swanston, C., Kleber, M., Filley, T., Kramer, M., Crow, S., Caldwell, B. A., Lajtha, K., and Bowden, R.: Organic C and $\mathrm{N}$ stabilization in a forest soil: evidence from sequential density fractionation, Soil Biol. Biochem., 38, 3313-3324, 2006.

Stockmann, U., Adams, M. A., Crawford, J. W., Field, D. J., Henakaarchchi, N., Jenkins, M., Minasny, B., McBratney, A. B., Courcelles, V. de R., Singh, K., Wheeler, I., Abbott, L., Angers, D. A., Baldock, J., Bird, M., Brookes, P. C., Chenu, C., Jastrow, J. D., Lal, R., Lehmann, J., O’Donnell, A. G., Parton, W. J., Whitehead, D., and Zimmermann, M.: The knowns, known unknowns and unknowns of sequestration of soil organic carbon, Agr. Ecosys. Environ., 164, 80-99, 2013.

Teh, Y. A., Diem, T., Jones, S., Huaraca Quispe, L. P., Baggs, E., Morley, N., Richards, M., Smith, P., and Meir, P.: Methane and nitrous oxide fluxes across an elevation gradient in the tropical Peruvian Andes, Biogeosciences, 11, 2325-2339, https://doi.org/10.5194/bg-11-2325-2014, 2014.

Totsche, K. U., Rennert, T., Gerzabek, M. H., Kögel-Knabner, I., Smalla, K., Spiteller, M., and Vogel, H.-J. : Biogeochemical interfaces in soil: The interdisciplinary challenge for soil science, J. Plant Nutr. Soil Sc., 173, 88-99, 2010.

Trumbore, S.: Radiocarbon and soil carbon dynamics, Annu Rev. Earth Pl. Sc., 37, 47-66, 2009.

Trumbore, S. E.: Comparison of carbon dynamics in tropical and temperate soils using radiocarbon measurements, Global Biogeochem. Cy., 7, 275-290, 1993.

Trumbore, S. E.: Potential responses of soil organic carbon to global environmental change, Proc. Natl. Acad. Sci. USA, 94, 8284 8291, 1997.

von Lützow, M., Kögel-Knabner, I., Ekschmitt, K., Flessa, H., Guggenberger, G., Matzner, E., and Marschner, B: SOM fractionation methods: Relevance to functional pools and to stabilization mechanisms, Soil Biol. Biochem., 39, 2183-2207, 2007.

Wander, M.: Soil organic matter fractions and their relevance to soil function, Soil organic matter in sustainable agriculture, CRC Press, Boca Raton, FL, 67-102, 2004. 
Wang, Q. and Wang, S.: Response of labile soil organic matter to changes in forest vegetation in subtropical regions, Appl. Soil Ecol., 47, 210-216, 2011.

Ward, S. E., Bardgett, R. D., McNamara, N. P., Adamson, J. K., and Ostle, N. J.: Long-term consequences of grazing and burning on northern peatland carbon dynamics, Ecosystems, 10, 1069-1083, 2007.

Zackrisson, O., Nilsson, M.-C., and Wardle, D. A.: Key ecological function of charcoal from wildfire in the Boreal forest, Oikos, 10-19, 1996.

Zimmermann, M., Leifeld, J., Schmidt, M. W. I., Smith, P., and Fuhrer, J.: Measured soil organic matter fractions can be related to pools in the RothC model, Eur. J. Soil Sci., 58, 658-667, https://doi.org/10.1111/j.1365-2389.2006.00855.x, 2007.
Zimmermann, M., Meir, P., Bird, M., Malhi, Y., and Ccahuana, A.: Litter contribution to diurnal and annual soil respiration in a tropical montane cloud forest, Soil Biol. Biochem., 41, 1338-1340, 2009.

Zimmermann, M., Meir, P., Silman, M. R., Fedders, A., Gibbon, A., Malhi, Y., Urrego, D. H., Bush, M. B., Feeley, K. J., and Garcia, K. C.: No differences in soil carbon stocks across the tree line in the Peruvian Andes, Ecosystems, 13, 62-74, 2010.

Zou, X. M., Ruan, H. H., Fu, Y., Yang, X. D., and Sha, L. Q.: Estimating soil labile organic carbon and potential turnover rates using a sequential fumigation-incubation procedure, Soil Biol. Biochem., 37, 1923-1928, 2005. 